\title{
TEMAS Y PERSONAJES MARGINALES EN ANDALUCÍA LA BAJA DE FERNANDO VILLALÓN
}

\author{
LYDIA S. RODRÍGUEZ MATA \\ Universidad de Málaga
}

Fernando Villalón es un gran hombre que vivió en Tartessos. Se despertó del sueño milenario ya viejo, viejísimo, con siglos a la espalda. Pero vejez de siglos es juventud auténtica. Primitividad. Por eso su voz suena madura y virgen. Con refinamiento pluriañoso, de andaluz macerado. Y con gracia de niño que juega desnudo con las fieras de Gerión.

E. GimÉnEZ CABALLERO ${ }^{1}$

\section{Introducción}

Fernando Villalón-Daóiz y Halcón (1881-1930) fue un caso singular y curioso dentro del grupo poético del 27. De hecho, Ángel González destaca el contraste que supone la figura de Villalón con la «profesionalidad y dedicación» de otros poetas:

Fernando Villalón, tan preciso y original, a veces, en la estilización de formas y temas populares, parece un escritor de otra estirpe, un afortunado poeta «de domingo» $»^{2}$.

${ }^{1}$ E. Giménez Caballero, «1928: Total de libros», La Gaceta Literaria, 50, 15 de enero de 1929, página tercera.

2 A. González, El grupo poético de 1927 (Antología), Taurus, Madrid, 1976, pág. 39.

$$
\text { [225] }
$$

AnMal, XL, 2018-2019, págs. 225-240 
A partir de esta aseveración, a lo largo de las páginas que siguen, queremos mostrar cómo la permeabilidad de este autor sevillano ante ciertos temas y personajes en su primera obra es marca inconfundible de originalidad y confirma su filiación como poeta de otro linaje.

Villalón fue noble (ostentaba el título de conde de Miraflores de los Ángeles), ganadero, garrochista y poeta tardío ${ }^{3}$ cuya actividad literaria quedó eclipsada por su conocida afición a los asuntos esotéricos y su carácter supersticioso, aspectos de los que dio buena cuenta su primo Manuel Halcón en Recuerdos de Fernando Villalón (1941) y que serán determinantes, como veremos a continuación, en la confección de algunos poemas.

El escritor sevillano no participó del mundo literario hasta que Andalucía la Baja (1926) vio la luz. Jacques Issorel nos informa de que la dedicación a la literatura coincide con su ruina económica, que le impide seguir ocupándose de la cría de los toros capaces de luchar en igualdad de condiciones con el diestro4. Sin embargo, Alberti recordaba en su conferencia sobre «Lope de Vega y la poesía contemporánea» que los quince millones de pesetas que le dejó la abuela en herencia se los «gastó, o tiró, en los negocios más poéticos»" El torero y dramaturgo Ignacio Sánchez Mejías lo consideraba «el mejor poeta novel de toda Andalucía» ${ }^{6}$. Ambos artistas fueron los exponentes de dos sociedades bien diferentes y alejadas en Sevilla — «la aristocracia rural» y «el mundo de los literatos $\gg\rangle^{7}-\mathrm{y}$ recibieron calificativos poco amables de Pedro Salinas, quien, en un principio, llamó a Villalón «perseguidor de la poesía», aunque posteriormente, en "El romancismo y el siglo XX», se corrigió y alabó la recuperación de asuntos y acentos que habían sido desterrados de la literatura y no habían recibido un tratamiento poético ${ }^{8}$. Precisamente, en el tratamiento de muchos de esos asuntos a los que alude Salinas es donde se condensan parte del mérito y aciertos del poeta sevillano. De hecho, Villalón, a pesar de su condición aristocrática, dirige su atención, como veremos más adelante, a los marginados: bandoleros, rufianes, contrabandistas, gitanos..., en definitiva, singulares personajes con los que el escritor actualiza la buscada influencia de Lope ${ }^{9}$, cuya producción hunde sus raíces en la tradición popular, sin perjuicio ni rechazo, claro está, del magisterio y genio aristocrático de Góngora.

${ }^{3}$ Su primer libro, Andalucía la Baja, ve la luz en 1926, cuando el autor tenía 46 años.

${ }^{4}$ F. Villalón, Poesías completas (ed. de J. Issorel), Cátedra, Madrid, 1998, pág. 12.

${ }^{5}$ R. Alberti, «Lope de Vega y la poesía contemporánea», en Prosas encontradas (ed. de R. Marrast), Biblioteca de Autores Andaluces, Barcelona, 2004, pág. 201.

${ }^{6}$ R. Alberti, Imagen primera de.., Seix Barral, Barcelona, 1999, pág. 68.

7 R. Reyes Cano, «El grupo poético del 27 y Sevilla: Crónica de un acto fundacional», Anales de Filología Hispánica, 3, 1987, 5-23, pág. 9.

8 Véase P. Salinas, Ensayos de literatura hispánica, Aguilar, Madrid, 1967.

${ }^{9}$ Dice Alberti: «el Lope de Villalón suele estar cruzado de toreros románticos, bandoleros de los llanos de Écija y la serranía de Córdoba» (R. Alberti, «Lope de Vega y la poesía contemporánea», pág. 201). 
A pesar de que la misteriosa personalidad de Villalón, amplificada por los muchos mitos que hicieron circular amigos y familiares, eclipsó su producción literaria, y a pesar incluso de que su actividad literaria apenas duró cuatro años (de 1926, año en que aparece Andalucía la Baja, a 1930, fecha de su muerte), las publicaciones del escritor nos muestran en su conjunto una obra seria, muy lograda, originalísima y de gran valor literario, empezando en el posmodernismo, pasando por el neopopularismo y neogongorismo, y terminando en el surrealismo. En palabras de Modesto Calderón Reina, «fue un neotradicionalista convencido en sus dos vertientes, tanto la neopopular como la neoclásica» y en ambas la mitología clásica jugó un papel muy importante ${ }^{10}$.

El poeta sevillano, considerado por muchos como escritor menor dentro del 2711, ha despertado mayor interés en el extranjero que en España. En 1944, José Luis Cano, quien conoció personalmente a Villalón en Málaga en el año 1928, se quejaba en un artículo de que no existían análisis concienzudos sobre su poesía, pues apenas se hallaban unas breves notas, insuficientes para caracterizarla ${ }^{12}$. Mientras en Francia e Italia, por ejemplo, empiezan a realizarse, a partir de la década de los 60, tesis sobre Fernando Villalón ${ }^{13}$, en España aún no existen investigaciones de estas características en donde se haya tomado a este poeta como serio y necesario objeto de estudio, pues lo que más proliferan son, a excepción de algunas honrosas excepciones, artículos y noticias en prensa que abundan en su doble y llamativa vertiente de poeta y ganadero.

En aquel mismo artículo, Cano cuestionaba la tan mencionada influencia de Lorca en la poesía de Villalón, algo que, a su parecer, no está suficientemente demostrado, ya que la lírica lorquiana, mucho más culta que popular, idealiza o ensalza el universo gitano, mientras que Fernando Villalón, con un acento más espontáneo y popular, «gusta de evocar estampas contrabandistas o marismeñas, con un fondo de toros salvajes» ${ }^{14}$. Por ello, propone como solución la posibilidad de estar ante dos ejemplos de inspiraciones paralelas y genuinas. A nuestro juicio, está claro que la experiencia rural y ganadera de Villalón en Andalucía permea toda su poesía, desde el primero hasta el último libro, y

${ }^{10}$ M. Calderón Reina, «La Andalucía helénica de Fernando Villalón: el edén perdido», en J. M. Maestre Maestre, J. Pascual Barea y L. Charlo Brea (eds.), Humanismo y pervivencia del mundo clásico. Homenaje al profesor Antonio Prieto, IV/1, Instituto de Estudios Humanísticos y CSIC, Alcañiz-Madrid, 2008, págs. 456-457.

${ }^{11}$ Por ejemplo, F. B. Pedraza Jiménez y M. Rodríguez Cáceres lo incluyen dentro del capítulo titulado «Poetas menores de la generación de las vanguardias» de su Manual de literatura española. XI Novecentismo y vanguardia: Líricos, Cénlit ediciones, Pamplona, 1993.

12 J. L. Cano, «El popularismo andaluz en la poesía de Villalón. Mito y leyenda de un poeta tardío», La Estafeta Literaria, 9, 1944, pág. 12.

13 Destacan especialmente la tesis de Jacques Issorel (Édition critique des oeuvres poétiques de Fernando Villalón, Universidad Paul-Valéry, Montpellier, 1980) y de Pilar Moyano (Fernando Villalón. El poeta y su obra, Potomac, Scripta Humanística, Maryland, EE.UU., 1990).

${ }^{14}$ J. L. Cano, «El popularismo andaluz en la poesía de Villalón. Mito y leyenda de un poeta tardío», pág. 12. 
coincidimos con Manuel Barrios en que es el «más apasionado conocedor de la Andalucía profunda $\gg^{15}$.

\section{Imagen de Andalucía en Andalucía la Baja}

Andalucía la Baja, su primera obra, se gestó a partir de la sección «Romances de tierra adentro», que en principio iba a publicarse como suplemento de la revista Mediodía. El libro se divide en siete partes de diferente extensión: «Las Tres Marías Atlánticas», «Momentos de la ciudad», «Momentos del campo», «Fotografías en verso», «El alma de las canciones», «Romances de tierra adentro» $\mathrm{y}$ «Rabel de "las tres Marías"». El título no deja de ser curioso por tratarse de una denominación tradicional, no oficial, pero común desde el siglo XVII, que marca la frontera que se establece entre las provincias de Cádiz, Córdoba, Sevilla y Huelva, por un lado (es decir, la Andalucía Occidental o Baja Andalucía), y las de Almería, Málaga, Granada y Jaén, por otro (la Andalucía Oriental o Alta Andalucía). El mapa de esa Baja Andalucía se perfila en el primer apartado del libro, «Las Tres Marías Atlánticas», cuyos poemas están dedicados a Sevilla («Hispalia»), Cádiz («Gadex» y «Los Puertos») y Huelva («Onnuba»). Huelva («Onnuba»), y el conjunto se cierra de manera perfecta con la última sección, «Rabel de 'Las Tres Marías'», que pone el acento sobre el aspecto musical y anuncia de manera sutil una división superior de la obra en dos bloques temáticos bien diferenciados y caracterizados a través de dos sentidos: la vista y el oído. Así, por un lado, tenemos el arte de la fotografía o de la pintura con los que se retratan y reproducen diversas escenas y escenarios («Las Tres Marías Atlánticas», «Momentos de la ciudad», «Momentos del campo», «Fotografías en verso»); y, por otro lado, tenemos la música, ya que a esta tierra también la define su rico patrimonio sonoro ( $« \mathrm{El}$ alma de las canciones», «Romances de tierra adentro» y «Rabel de 'Las Tres Marías'»). En definitiva, el título de Andalucía la Baja anticipa al lector posibles contenidos: espacio, tema, personajes, tiempo, etc.

El libro ha sido considerado por Manuel Halcón y Jacobo Cortines como una obra carente de unidad en su composición, sin elemento vertebrador. Así, dice Cortines:

[...] la obra, no exenta de méritos y aciertos, se resiente de cierta falta de unidad y acusa mezcla de estéticas diferentes: desde el posmodernismo hasta los ribetes vanguardistas, pasando por el neopopularismo ${ }^{16}$.

\footnotetext{
${ }^{15}$ M. Barrios, Ronda de los bandoleros, Fundación José Manuel Lara, Sevilla, 2004, pág. 9.

${ }^{16}$ En V. García de la Concha (ed.), Poetas del 27: La generación y su entorno. Antología comentada. Fernando Villalón (Selección y comentarios de J. Cortines), Espasa Calpe, Madrid, 1998, pág. 649.
} 
Pero Felipe B. Pedraza y Milagros Rodríguez reconocieron que el hilo conductor se manifiesta a través de un viaje por tierras andaluzas «en el que se da cabida a la geografía, la historia y la leyenda, los tipos y costumbres, las danzas y tradiciones populares» ${ }^{17}$. En conjunto, es un libro importante no solo por su temática y sus personajes (gitanos, cofrades, contrabandistas, cazadores, bandoleros, mendigos...), sino porque los textos que se reúnen en el apartado «Romances de tierra adentro» constituyen una «reivindicación del romance popular bajo nuevas formas cultas $\rangle^{18}$. Además, como señala Jacques Issorel, la obra contrapone la imagen real de Andalucía a esa otra pintoresca que ofrecían los viajeros románticos, «como en un escaparate a la mirada de los extraños» ${ }^{19}$ :

¡Oh corral sevillano...! ¡Oh panal donde moran las abejas obreras con su reina y su zángano...! Eres el triste estigma de mi Sevilla de ahora aunque en Norte de América gusten mucho de tus cuadros...

Es importante recordar aquí que, hasta casi la mitad del siglo XX, muchas de las publicaciones existentes sobre Andalucía venían a reproducir tópicos difundidos a través de la literatura romántica del XIX por parte de viajeros de la época como Laborde, Théophile Gautier, Hare..., cuyo objetivo no era otro que desvirtuar la imagen real de la etnia gitana, confiriéndole un rasgo de bohemia añorada, o, en el mejor de los casos, explotar hasta la saciedad una imagen folclórica.

A finales ya del siglo XVIII y a lo largo del XIX, muchos escritores descubrieron en esas imágenes de bandoleros, contrabandistas y gentes errantes los símbolos de una libertad a la cual aspiraban. En líneas generales, el extranjero solía tener una visión estereotipada de todo lo andaluz y lo gitano, que acababa suplantando la imagen real y, con el paso del tiempo, desembocaría en esa España de pandereta.

En el siglo XIX, según informa el profesor José Ortega, «el folklore andaluz (gitano) tiene una recreación literaria basada en el pintoresquismo» ${ }^{20}$. Así, el viajero-escritor, quien solía llegar con una serie de ideas y prejuicios, se limitaba a reforzar esa visión a través de sus escritos. Tómense como ejemplo las negativas palabras que Laborde (París, 1773-1842) dedica a los gitanos en Itinéraire descriptif de l'Espagne, et tableau élémentaire des différents branches de l'administration et de l'industrie de ce royaume:

Andalucía fue, en otro tiempo, refugio de gitanos, esa especia pérfida y peligrosa, sin hogar ni patria, sin fe y sin ley, que era la peste de España,

\footnotetext{
${ }^{17}$ F. B. Pedraza Jiménez y M. Rodríguez Cáceres, op. cit., pág. 267.

18 J. L. Cano, La poesía de la generación del 27, Guadarrama, Madrid, 1970, pág. 57.

${ }^{19} \mathrm{~F}$. Villalón (ed. de J. Issorel), op. cit., págs. 24 y 27.

$20 \mathrm{~J}$. Ortega, «El gitano y el negro en la obra de García Lorca», Cuadernos Hispanoamericanos, no 433-434, 1986, 145-168, pág. 146.
} 
el oprobio de la nación que la sufría, el terror de los caminos y de los campos, que por fin el gobierno español ha proscrito con leyes severas ${ }^{21}$.

\section{Temas de Andalucía la Baja}

Esa imagen real de Andalucía que pretende enseñar Villalón en su obra atraviesa de alguna forma todos los temas que se entretejen en Andalucía la Baja, entre los que se pueden espigar los siguientes:

- Pasado mítico de Andalucía: destacan las composiciones dedicadas a Sevilla («Hispalia»), Cádiz («Gadex») y Huelva («Onnuba»), dentro de «Las tres Marías atlánticas». De la fundación de Híspalis por Hércules de Libia, hijo de Osiris, se habla en los poemas «Holocausto» e «Hispalia. En el primero de ellos leemos:

Fieles seguimos a tu santo rito ¡oh Hércules de Libia! Dios de Hispalia. Yo me arrodillo y beso tu sandalia, revestido de cíngulo y amito.

- Pasado histórico: fenicios, romanos, cartagineses, Reyes Católicos, el descubrimiento y conquista del Nuevo Mundo... Los ejemplos se multiplican en varios poemas. Sirvan para ilustrar esto unos versos de «Gadex»:

Gadex se habrá marchado en busca del tesoro de la ciudad atlante de las Puertas de Oro, que la musa de Homero nos cancionó gloriosa.

Las antiguas poblaciones ibéricas despiertan, en la década de 1920, el interés de muchos escritores y estudios. Títulos como Tartessos. Contribución a la historia más antigua de Occidente (1924) ${ }^{22}$ de Adolf Schulten ${ }^{23}$, publicado por Revista de Occidente, avalan el interés por el estudio del legado arqueológico de aquella ciudad. Ese gusto y afición por el pasado mítico y milenario de Andalucía desempeña también un papel importante en la vida y obra del poeta sevillano. De hecho, parece que el autor estaba obsesionado con que sus propios toros herbajaran en las marismas de Huelva y Sevilla:

${ }^{21}$ M. Bernal Rodríguez, La Andalucía de los libros de viajes del siglo XIX, Editoriales Andaluzas Unidas, Barcelona, 1985, pág. 54.

${ }^{22}$ La obra apareció originalmente en lengua alemana, en 1922. Tartessos. Ein Beitrag zur ältesten Geschichte des Westens, Friederichsen, Hamburgo, 1922.

${ }_{23}$ Motivado por la Ora maritima de Avieno y tomando como ejemplo el trabajo de Heinrich Schliemann, quien encontró y excavó las ruinas de Troya tomando a partir de las referencias proporcionadas en la Ilíada de Homero, Schulten acomete la difícil empresa de demostrar que Tartessos se localizaba en las marismas de Doñana. 
[...] en esta tierra que piso, cuna de la civilización ibérica, el Hércules egipcio, hijo de Osiris, fundador de Hispalia, dio la primera nota taurina en el mundo. Aquí fue su lucha decisiva con Gerión, tirano de Tartesos, para arrancarle la posesión de los célebres toros colorados que guardaba el temible perro Orthos ${ }^{24}$.

- Andalucía rural: la pasión por sus campos y el trabajo en torno a ellos le impulsaron a dedicarse a las actividades de ganadero primero y poeta después ${ }^{25}$. Véanse, por ejemplo, los poemas «Las Eras» y «La Jarria»»26:

Van las yeguas enlazadas por los cuellos cual culpables a cadenas sometidas y en la calma amarilla de la siesta cruje el látigo.

Merece la pena que nos detengamos en la imagen de esa «calma amarilla de la siesta» y veamos su importancia en el conjunto de la escena. Obsérvese en estos versos el feroz contraste que se establece entre la siesta y el látigo, el cual nos recuerda a ese otro momento, en uno de los romances del siglo XIII dedicados a los siete infantes de Lara, en que la siesta (tiempo después del mediodía, en que aprieta más el calor) resulta esencial para el repentino y trágico desenlace:
A cazar va don Rodrigo,
y aun don Rodrigo de Lara;
con la gran siesta que hace,
arrimándose ha una haya,
maldiciendo a Mudarrillo,
hijo de la renegada,
que si a las manos le hubiese,
que le sacaría el alma.

Otro ejemplo de la Andalucía rural lo hallamos en «La Jarria»:

Ya suena la zumba, ya viene la jarria.

Los asnos parduzcos y rucios ya vienen

por la senda estrecha. Ya asomó el primero

$\mathrm{y}$ al pararse en firme todos se detienen...

- Andalucía cofrade, romera y devota de vírgenes: como la de Regla, la Macarena y la del Rocío, a la que se pide auxilio y se dirigen promesas en momentos de máxima desesperación, como el que le toca vivir al joven patrón del poema «Con la proa a Punta Montijo»:

${ }^{24}$ M. Halcón, Recuerdos de Fernando Villalón, Alianza, Madrid, 1969, págs. 108-109.

${ }^{25}$ «El amor por esa tierra original, que pisara Hércules, se traslada de una vocación a otra» (M. Calderón Reina, art. cit., pág. 456).

${ }^{26}$ Andalucismo de «arria». 
Amarrado va al timón,

los golpes del mar temiendo, el joven patrón, que es joven pero que en la mar es viejo. «iMadresita mía de Regla, madre de los marineros, que de los vientos del mar, tienes el rostro moreno!

\section{[...]}

¡Yo te prometo un barquito, y dos velas te prometo!

$$
[\ldots]
$$

y un mascarón muy compuesto

con figura de mujer

y la cara de Consuelo

$\mathrm{y}$ una leyenda que diga

"Vijen, a ti te la debo"».

Como todo ritual o fiesta a la que concurre el grupo entero (la sociedad total), en la Semana Santa, la experiencia de sociabilidad es intensa. A ella acuden personas de distintos estratos sociales y con motivaciones diferentes (religiosas, estéticas, místicas...), pero todos hablan entre sí e incluso los espectadores se atreven a abordar a los nazarenos, como vemos en «El Armado de la Macarena». En ese texto, el poeta de Morón coloca a un mismo nivel el humor, el erotismo y la religiosidad de uno de esos desfiles de pasión, en donde el sujeto lírico se pregunta quién recluta a los armados de la Virgen Macarena, llega a valorar la estatura y paso de los nazarenos, y se ríe ante la posibilidad de que uno de esos mozos «armados» se dirigiera marcando el paso hacia la ventana de su novia y provocara la risa de todos:

¿Por qué son tan enanos

estos seudo-romanos?

\section{$[\ldots]$}

¿Y el suave contoneo

que usan en el paseo...?

Los soldados de Augusto,

según la Historia el verlos daba susto...

Luego el gentil meneo

de aquestos macarenos, no es copiado,

que nunca fue condición de aquel soldado semejante pasito,

y menos debe serlo de un armado mocito que se precie de tal. 
- Andalucía musical: con sus cantes tradicionales (las nanas, las sevillanas...), flamencos (la siguirilla, el martinete...) y de ida y vuelta (como la guajira). La obra cuenta con una sección propia, «El alma de las canciones», constituida por 15 poemas, y de alguna manera entronca con el interés por los temas más característicos de la literatura de fines del XIX y principios del XX. Basta echar un vistazo a la ingente lista de publicaciones de aquellos años: El alma castellana (1900) de Azorín, El alma española: Ensayo de una psicología nacional (1908) de Gustavo de la Iglesia, Alma andaluza (1900) de José Sánchez Rodríguez, etc.

En lo que a esta parte del libro se refiere, «El alma de las canciones» es la original contribución del poeta sevillano a la difusión de la rica tradición musical. Así, el poema «Las sevillanas» pone el acento en el ambiente que se respira en las noches de abril, mes en que se celebra la feria de Sevilla:

Trinos de cristal y plata.

$$
[\ldots]
$$

Fragancias de mes de abril

Bajo la falda planchada.

El poema «La malagueña» realiza un rápido recorrido por alguno de los palos más representativos del flamenco:

La soleá es el llano...

La siguirilla, fragua...

La malagueña pura,

la Sierra de Granada...

¡Oh rey de los ingenuos...

fandanguillo de Huelva....!

que hueles a romero,

como huelen tus sierras

de Aroche y de Aracena...

Sentidas granaínas.

Cartageneras tiernas.

¡Oh cantes del Levante

que de Granada eran...!

En «El tango» se explica el origen y significado de este cante de ida y vuelta, que no es patrimonio ni de payos ni de gitanos:

Canto de los burdeles, tango cubano que por Cádiz entraste con tus charangas, los danzones criollos son tus hermanos y juntas te cantaron Cuba y España.

Ni gachó ni flamenco. De todo tienes. 
Y las «Guajiras» aparecen hermanadas con la poesía romántica de Bécquer:

Negrito que trajo el barco en su bodega escondido, tú que de Cuba has venido a Cádiz saltando el charco.

\section{$[\ldots]$}

Ya tus cantares guajiros se mezclan con otros cantes. Profesionales bergantes le dieron flamencos giros; tus primitivos suspiros que olían a piña y caña huelen hoy a manzanilla y te canta el Sur de España con letra de siguirilla.

$$
\text { [...] }
$$

¡Oh romántica guajira! ¡Bello canto! ¡Fiel mixtura, del cariño y la amargura, de una esclavizada lira...! Gustavo Bécquer te tira Besos desde su ataúd...

- Andalucía esotérica: ya apuntamos al principio su gusto por los asuntos esotéricos. En lo que respecta a sus poemas, en algunos versos la noche adquiere un carácter mágico por la presencia de seres extraños (como la bruja) y animales nocturnos que la pueblan (algunos considerados siniestros, como la lechuza, a la que antiguas supersticiones han asociado a desastres). En el folklore y creencias de muchos pueblos, bruja y lechuza forman un tándem funesto y maldito por su disposición a la hora de generar desgracias. De hecho, desde antiguo se creía en la capacidad de metamorfosis de ambos seres: la bruja, en lechuza; la lechuza, en bruja. En el poema «El sereno de la aldea», encontramos al poeta pidiendo al sereno que cante para conjurar cualquier mal o un indeseable encuentro con dos mujeres pecadoras, contrafiguras de la mujer católica desde la Edad Media: una maléfica, por su encarnación del mal (la bruja), y otra impura (la prostituta):

$$
\begin{aligned}
& \text { Yo... estoy asustado } \\
& \text { sereno cantor... } \\
& \text { Canta, canta, canta... Canta por favor. } \\
& \text { Las noches de invierno zumbantes de viento } \\
& \text { chocan los portones sus goznes tascando... }
\end{aligned}
$$


Tras del ventanuco un candil humea...

La lechuza vuela... ¿Te pasó rozando?

Es que la lechuza va tarde a la cita...

En la fuente esperan al ave maldita...

la Bruja y la lea.

En «El ciclista» leemos:

Las viejas del pueblo dicen

que una bruja es tu madrastra

y que cuando duermes llega

en silencio a tu almohada,

te unta el cuerpo con manteca,

te reza la abracadabra,

enciende tu único ojo

$\mathrm{y}$ ata un mensaje a tu espalda

para su esposo el Demonio

y a esos caminos te lanza,

oprimiendo entre tus piernas

el espaldar de tu cama...

- Viejos oficios que hoy se están perdiendo — el afilador, el lañador, el farolero, el esquilador, el sereno... - perviven, por su fiel retrato, en los versos de Andalucía la Baja. Los ejemplos se suceden sin apenas interrupción a lo largo de casi toda la obra. Destacamos unos versos que inmortalizan la labor del lañador, cuya pericia y buen hacer es equiparable a la del médico:

Yo tengo un lebrillo moruno y brillante.

$$
[\ldots]
$$

Por eso al notar una leve rotura

me ocupo en persona de su compostura.

Llamo al lañador que ausculta.

Extrae un instrumento de su alforja de urgencia

y lo opera de lañas en mi presencia...

\section{$[\ldots]$}

pues son los cirujanos de nuestro arte perdido.

Curanderos de la Imaginería.

\section{Personajes de la sociedad andaluza}

La estructura de la sociedad andaluza a finales del siglo XIX la conformaban cuatro grandes grupos: en primer lugar, los terratenientes, que con frecuencia poseían títulos nobiliarios; en segundo lugar, se hallaba la oligarquía financiera; en tercer lugar, se encontraría una clase media poco representativa, formada 
por comerciantes, funcionarios y algunos profesionales; y el último lugar de la escala lo ocuparía la clase pobre y trabajadora (jornaleros, pequeños propietarios, etc.). La diferencia de clases, como se ve, generaba una injusta desigualdad económica que se mantuvo más allá de la segunda mitad del siglo XX. De hecho, hasta esas fechas, en la Andalucía Occidental o Baja Andalucía, más de dos tercios de la población pertenecían a la clase trabajadora, frente a la clase alta ( $1 \%$ ) y clase media (35\% aproximadamente). A pesar del inmovilismo que caracteriza a estos grupos y de la dificultad que entraña escapar de la pobreza, se hallaban excepcionales casos de movilidad vertical y de liberación del yugo que oprimía a los más desfavorecidos. Sirva de ejemplo la siguiente estrofa del poema «Campiña de Utrera», donde vemos el ascenso social del nieto de antiguos labradores, que pasa de desplazarse en jaca a conducir un coche Ford vestido a la manera de los nobles ingleses:

En la puerta del cortijo para un Ford.

Es el amo. Ya no llega en su jaca como antes...

Es un nieto de los viejos labradores caminantes

y jinetes atrevidos que murieron. Va vestido de milord.

La mayoría de los personajes que pueblan Andalucía la Baja aparecen perfectamente representados en la sección III (Figuras) del apartado «Fotografía en verso»: el fraile popular, el bandido, el torero, el amante de la señorita, el novio viejo, el genealogista, el rufián que vende romances, el contrabandista... Todos ellos dibujan el paisaje de geografía humana. De modo que, a través de varios poemas, podemos hacernos una idea sobre la estructura de población que caracterizaba a muchos pueblos y ciudades de esa baja Andalucía en un momento determinado de su historia. En este sentido, resulta especialmente significativo el poema que abre el libro, «Dedicatoria», que reconoce y saluda a sus destinatarios predilectos:

A ti que llevas una cruz a cuestas,

$$
[\ldots]
$$

A ti rufián... A ti ladrón-artista.

Al bandolero y al contrabandista que por la libertad dan la pelleja...

$[\ldots]$

¡Salve, oh escoria de mi patria vieja...!

Más allá de una ligera simpatía, el contrabandista goza de manera especial de la comprensión y el apoyo de Fernando Villalón, que lo presenta frente a su antagonista, el carabinero, que es a la vez fuente de sus problemas y pesares. El procedimiento recuerda a ese otro binomio antitético en Lorca: gitano y guardia civil. Véanse como ejemplo estos versos del poema «Contrabandista valiente»: 


\begin{abstract}
Si no me mienta a mi madre
el carabinero aleve,

ni yo le quito la vida

ni me pierde para siempre.$$
[\ldots]
$$

Si no me mienta a mi madre

el carabinero aleve,

no lo mata de aquel tajo

mi cuchillo de Albacete, aquél que tenía un letrero en su hoja, fina y fuerte, que decía: Biba mi Dueño, Contrabandista Baliente.
\end{abstract}

Al igual que el contrabandista, otros personajes nimbados por la marginalidad o vida bohemia aparecen en escena junto a su contrapunto o antagonista. Muchos representan conductas antisociales, ya que, por sus acciones contra el entorno, personas o propiedades, infringen reglas y expectativas de los otros, esos que conforman el resto de la sociedad. Así, encontramos a una joven gitana llorando frente al juez de instrucción de El Saucejo por su amante preso; hallamos al cazador furtivo en contraposición a la Benemérita; vemos al mendigo frente al jinete «nazareno caballista»; y contemplamos a unos bandidos frente al guarda montaraz.

En el poema «El pozo de la cañada», se dice del haraposo y desaseado pordiosero:

\author{
A la sombra de la higuera ronca un pobre \\ pordiosero, boca arriba y el petate bajo el cuerpo. \\ De sus rotas vestiduras brota el vello... \\ los cabellos en desorden... a sus pies se enrosca un perro.
}

Y en «Campiña de Écija» canta al bandido que se convierte en guardia:

En la Sierra de Estepa, Marinalea y Osuna

no hay mejor caballista que el Tuerto de Porcuna,

el guarda montaraz.

Por otro lado, también hay que destacar la defensa de la herencia genética y cultural musulmana en «Campiña de Jerez». Los musulmanes, sin ser marginales, comparten con los gitanos el hecho de haber sido objeto de hostigamiento, persecución e integración desde la política de unificación de los Reyes Católicos. En definitiva, también fueron anatema; pero hay algo que no pudieron exterminar: esa belleza tan característica de las mujeres de esa tierra solo puede ser fruto de la herencia que dejaron las féminas que trajo Tariq Ibn Ziyad a Al Ándalus en el siglo VIII y que se reprodujeron durante 700 años por estas 
tierras. Los versos que aparecen a continuación se hacen eco de un tema propio del modernismo «orientalista» al tiempo que revelan la maurofilia del poeta:

$$
\begin{aligned}
& \text { [...] y mujeres morenas de rizadas pestañas, } \\
& \text { nietas de las que trajo Tarik a las Españas } \\
& \text { y aquí por siete siglos, parieron sin cesar... } \\
& \text { ¡Nunca podrá Castilla vuestra casta borrar...! }
\end{aligned}
$$

Otros personajes de gran calado que pueblan la obra son los gitanos. Destacamos la compasión que rezuman algunos versos ante el padecimiento de esta etnia y la asunción de responsabilidad por parte del poeta (muy cerca de la culpa y de la compunción) ante los distintos procesos y políticas de asimilación que llevaron a cabo durante siglos los monarcas españoles, en aras de una supremacía cultural, a través de crueles pragmáticas y constantes persecuciones («una raza que todos perseguimos»). Así, en «La Siguirilla gitana y el Martinete», dice:

$$
\begin{aligned}
& \text { ¡Esclavos de una culpa que todos cometimos! } \\
& \text { ¡Pobrecitos gitanos ignorantes y artísticos! } \\
& \text { ¡Son vuestros martinetes los más característicos } \\
& \text { cantares de una raza que todos perseguimos...! }
\end{aligned}
$$

La historia del pueblo gitano, presente en España desde el año 1425 (o incluso puede que antes) es la historia de la discriminación, el agravio y la marginación a la que se ha visto sometido un pueblo que en el siglo XX seguía siendo un gran desconocido para la sociedad mayoritaria, que ignoraba su cultura y su derecho a ser diferentes.

Aunque en un principio disfrutaron de una etapa idílica con la concesión de salvoconductos y permisos especiales que les permitían el desplazamiento por toda la geografía sin despertar la más mínima desconfianza, pronto se empezó a mirar con recelo su constante nomadismo y ya a finales del siglo XV, en 1499, se hizo pública la primera pragmática antigitana, dictada por los Reyes Católicos y conocida con el nombre de Pragmática de Medina del Campo.

Casi al final de «La Siguirilla gitana y el Martinete», Villalón deja claro su conocimiento de la historia (origen indio, éxodo y persecuciones) del pueblo gitano. $\mathrm{Y}$ es precisamente del conocimiento, del saber y de la conciencia de donde emerge la culpa:

Si a vuestra patria ignota llegáis una mañana y un rey sabio y prudente rige vuestros destinos, mandará un sacerdote que por esos caminos en un cáliz recoja las lágrimas gitanas...

La inclusión de personajes gitanos en esta obra de Villalón justifica la presencia del léxico caló en sus poemas, en perfecta convivencia con voces 
de la lengua francesa (por ejemplo: chauffeur, coiffeur), italiana (por ejemplo: razziadas) ${ }^{27}$, portuguesa (por ejemplo: saudades), alemana (por ejemplo: $\left.k u r s a l\right)^{28}$ e incluso alguna que otra voz inventada por él mismo (como «andaluciano»). En alguna ocasión, sorprende incluso encontrar dos voces para aludir a un mismo concepto. Por ejemplo, en el poema «El afilador», encontramos a un hombre seductor de «pecho apolíneo» y «color trigueño», que pregunta a una mujer: «Joven... ¿tendría tixeras que afilar o amolar?» ${ }^{29}$.

El ejemplo más ilustrativo lo encontramos en «La Siguirilla gitana y el Martinete», dedicado a su hermano Jerónimo, del que dice que es a la vez un «exquisito chanelao ${ }^{30} \mathrm{y}$ distinguido sportman»:

Qué ducas ${ }^{31}$ ma grandes,

compañera mía,

er s'esclavito de los moros malos

e la Berbería.

Los gachós no pesquibá este cante juncá, que mangue a un zincaló se le oye guillabá al son del currandó sobre el estruje ${ }^{32}$ duro que son los violines del calorró más puro.

\section{[...]}

Ar que pandibó a mangue

no le jagan daño,

que mojo le críe un churi amolao

dentro e los reaños ${ }^{33}$.

${ }^{27}$ Saqueadas (del italiano razzia, «saqueo»). Aquí el adjetivo femenino plural se forma con la desinencia de la lengua española a fin de alcanzar la concordancia en género y número que viene marcada por el sustantivo «mieses».

${ }^{28} \mathrm{La}$ inclusión de galicismos, anglicismos y otros términos en lenguas extranjeras es un recurso bastante común en la corriente ultraísta. De hecho, la palabra Kursaal, que, aunque se use como sinónimo de local nocturno, significa balneario, la emplean otros poetas de la época (como Isaac del Vando Villar en su caligrama titulado «En el infierno de una noche»). La voz era bastante popular en esa época. De hecho, en Madrid, en la Plaza del Carmen, había un local llamado Gran Kursaal, muy frecuentado por la bohemia de la época; y en Sevilla, hasta 1935, el Kursaal Internacional fue una emblemática sala de espectáculos, situada en las calles O'Donnell, San Antonio y Sierpes, en el que actuaron figuras míticas del cante como Manuel Torre, El Cojo de Málaga y un jovencísimo Antonio Mairena.

${ }^{29}$ Verbo en caló que significa «afilar».

${ }^{30}$ Del verbo en caló chanelar, que significa «entender». En este caso, se refiere a que es un entendido en el flamenco.

${ }^{31}$ Penas en caló.

32 Más común, astruje o trujé.

33 «Los gachós (los no gitanos) no entienden este cante bueno/ que le escuché cantar a un gitano/ al son del martillo sobre el duro yunque/ que son los violines del gitano más puro. [...] Al que me encarceló/ no le hagan daño,/ que un cuchillo afilado le críe moho/ en las entrañas». *Traducción de Lydia Rodríguez Mata y Miguel Ángel Vargas. 


\section{Conclusión}

Andalucía la Baja supone una clara reivindicación y promoción de temas y personajes poco comunes en la literatura y, especialmente, en la poesía, con la clara intención de romper con esa imagen tópica y pintoresca que, hasta la fecha, habían difundido por Europa los viajeros románticos. Así, frente a esa imagen estereotipada, Fernando Villalón ensalza el pasado mítico e histórico de Andalucía, las actividades agrícolas y ganaderas de esta región, el fervor religioso de sus gentes, sus creencias esotéricas, sus cantes tradicionales, sus viejos oficios, etc.

En lo que respecta a los personajes que pueblan la obra (el torero, el rufián, el contrabandista, el joven amo nieto de antiguos labradores que asciende socialmente...), estos componen el paisaje de geografía humana y ofrecen una imagen muy certera de la estructura de población de muchos pueblos y ciudades de Andalucía en esa época. Por supuesto, sus personajes predilectos son los marginados, algunos de los cuales representan conductas antisociales, como el gitano, el cazador furtivo, el mendigo, los bandidos... Entre todos ellos, destacan especialmente los gitanos, por los que muestra no sólo compasión, sino también admiración, tal y como se ve en el profundo conocimiento de su historia, dialecto y cultura.

En conclusión, los ejemplos aquí expuestos confirman que nos hallamos ante una de las obras poéticas más originales de la década de 1920 y muestran cómo los escenarios, asuntos, acentos $\mathrm{y}$, sobre todo, los personajes que pueblan Andalucía la Baja solo pueden ser correctamente interpretados «dentro de esa estética de refinado popularismo y de matizada exaltación folklórica que abrazaron los hombres del $27 \gg^{34}$.

\footnotetext{
${ }^{34}$ R. Reyes Cano, op. cit., pág. 9.
} 